\title{
Using ensemble-mean climate scenarios for future crop yield projections: a stochastic weather generator approach
}

\author{
Di Ma ${ }^{1,2}$, Qi Jing ${ }^{2}$, Yue-Ping $\mathrm{Xu}^{1}$, Alex J. Cannon ${ }^{3}$, Taifeng Dong ${ }^{2}$, \\ Mikhail A. Semenov ${ }^{4}$, Budong Qian ${ }^{2, *}$ \\ ${ }^{1}$ Institute of Hydrology and Water Resources, Zhejiang University, Hangzhou 310058, PR China \\ ${ }^{2}$ Ottawa Research and Development Centre, Agriculture and Agri-Food Canada, Ottawa, ON K1A 0C6, Canada \\ ${ }^{3}$ Climate Research Division, Environment and Climate Change Canada, Victoria, BC V8W 3R4, Canada \\ ${ }^{4}$ Rothamsted Research, Harpenden, Hertfordshire AL5 2JQ, UK
}

\begin{abstract}
Using climate scenarios from only 1 or a small number of global climate models (GCMs) in climate change impact studies may lead to biased assessment due to large uncertainty in climate projections. Ensemble means in impact projections derived from a multi-GCM ensemble are often used as best estimates to reduce bias. However, it is often time consuming to run process-based models (e.g. hydrological and crop models) in climate change impact studies using numerous climate scenarios. It would be interesting to investigate if using a reduced number of climate scenarios could lead to a reasonable estimate of the ensemble mean. In this study, we generated a single ensemble-mean climate scenario (En-WG scenario) using ensemble means of the change factors derived from $20 \mathrm{GCMs}$ included in CMIP5 to perturb the parameters in a weather generator, LARS-WG, for selected locations across Canada. We used En-WG scenarios to drive crop growth models in DSSAT ver. 4.7 to simulate crop yields for canola and spring wheat under RCP4.5 and RCP8.5 emission scenarios. We evaluated the potential of using the En-WG scenarios to simulate crop yields by comparing them with crop yields simulated with the LARS-WG generated climate scenarios based on each of the 20 GCMs (WG scenarios). Our results showed that simulated crop yields using the En-WG scenarios were often close to the ensemble means of simulated crop yields using the 20 WG scenarios with a high probability of outperforming simulations based on a randomly selected GCM. Further studies are required, as the results of the proposed approach may be influenced by selected crop types, crop models, weather generators, and GCM ensembles.
\end{abstract}

KEY WORDS: Global climate models $\cdot$ LARS-WG $\cdot$ DSSAT $\cdot$ Wheat $\cdot$ Canola $\cdot$ Simulation

\section{INTRODUCTION}

Climate change has significant impacts on various systems worldwide, including ecology, hydrology, and agriculture (IPCC 2014). Climate change impact assessments are essential to developing policies and strategies for climate change adaptation and mitigation. Climate change impact studies are often based on modelling results using future climate scenarios to drive impact models, such as hydrological models for water resources, crop growth models for crop produc-

*Corresponding author: budong.qian@canada.ca tion, and ecosystem models for the environment. Global climate models (GCMs) are the major tools used to project future climate scenarios, and their outputs are often used in the studies of climate change impacts (e.g. Qian et al. 2016a,b, Al Samouly et al. 2018). An increasing number of GCMs have been available in recent years (Lutz et al. 2016). Moreover, improvements in other aspects of climate modelling are incorporated in the Coupled Model Intercomparison Project Phase 5 (CMIP5), including a new set of emission scenarios, i.e. representative concentration

(- Her Majesty the Queen in Right of Canada, as represented by the Minister of Agriculture and Agri-Food Canada. Open Access under Creative Commons by Attribution Licence. Use, distribution and reproduction are unrestricted. Authors and original publication must be credited. 
pathways (RCPs) (Moss et al. 2010). In spite of improvements in CMIP5, uncertainty in climate projections is still large due to differences in model response, forcing scenarios, and internal climate variability. Thus, it is recommended to use multi-model ensembles in climate change impact studies to reduce potential biases in impact projections (Semenov \& Stratonovitch 2010). For example, Gao et al. (2019) assessed the responses of hydrological processes to climate change over the southeastern Tibetan Plateau using 18 GCMs in CMIP5. Qian et al. (2019a) conducted a comprehensive evaluation of climate change impacts on Canada's crop production under different levels of global warming based on $20 \mathrm{GCMs}$.

However, it is often time consuming to run processbased models, such as watershed hydrological models or crop growth models, in climate change impact studies when a large number of climate scenarios are used. For example, in a recent study (Webber et al. 2018), simulations were run on 8157 grids in Europe to estimate the impact of climate change on wheat and maize using 10 crop models and 5 GCMs. The ensemble means provide essential information to policymakers and the general public, as ensemble means can serve as a best estimate for the impact of climate change (Challinor et al. 2018). Moreover, using ensemble means will reduce bias in assessments where only $1 \mathrm{GCM}$ is used. For example, Qian et al. (2020) found that projections of crop production in Canada using climate scenarios from 1 climate model differ substantially from the ensemble means derived using climate scenarios from multiple GCMs in CMIP5. Moreover, multiple runs of the GCMs, i.e. perturbed physics ensembles (PPEs), are often available, but only 1 run (member) of the GCMs is often used in climate change impact studies where the multi-GCM approach is adopted. Large uncertainty due to internal climate variability was quantified for crop yield projections in Canada using large ensembles of 1 GCM and 1 regional climate model (Qian et al. 2020). Therefore, it is practically useful if a single climate scenario representative for climate change scenarios from multiple GCMs, and particularly multiple members of PPEs, can be generated to drive process-based impact models for efficient estimation of ensemble means in climate change impact studies. Adopting this approach may substantially reduce the use of resources in running simulations with climate scenarios from a large and increasing number of GCMs and PPEs to derive ensemble means, thus freeing up resources for other aspects in climate change impact and adaptation studies, in addition to reducing bias.
It has been reported that multi-model averaging can enhance the reliability of climate projections (Wang et al. 2017, Al Samouly et al. 2018), largely resulting from the cancellation or compensation of errors in the individual models even on the regional scale (Pierce et al. 2009). However, directly averaging daily climate outputs from multiple climate models to drive process-based models is not applicable because averaging smooths climate variability. It is even more difficult, if not impossible, to develop such a single scenario by averaging GCMs, as the relationship between climate variables and their impacts may not be linear (Wang et al. 2018, Whitfield \& Cannon 2000).

In this study, we attempted to generate the aforementioned single ensemble-mean climate scenarios (En-WG scenarios) by using ensemble means of the change factors derived from 20 GCMs in CMIP5 to perturb distributions of the site parameters of climatic variables in the Long Ashton Research Station Weather Generator (LARS-WG) (Semenov \& Barrow 1997). The generated En-WG scenarios for 2 future periods (2040-2069 and 2070-2099) under RCP4.5 and RCP8.5 were used to drive crop growth models in the Decision Support System for Agrotechnology Transfer (DSSAT) ver. 4.7 (Hoogenboom et al. 2017) to simulate yields for 2 major crops (canola and spring wheat) at selected locations across Canada. Simulated crop yields using the En-WG scenarios were compared with the ensemble means of simulated yields using 20 climate scenarios generated by perturbing the LARS-WG site parameters with change factors estimated from each of the $20 \mathrm{GCMs}$ (WG scenarios), for the same future periods and RCPs. The objective of this study was to investigate the potential of generating 1 single ensemble-mean climate scenario (En-WG), using a stochastic approach based on multiple GCMs, for estimating crop yields and to compare them with the ensemble means of simulated crop yields using individual climate scenarios (WG scenarios) from the multi-GCM ensemble under different RCPs.

\section{MATERIALS AND METHODS}

\subsection{Study areas}

In this study, we selected 10 locations with diverse climatic conditions and soils, covering agricultural production areas across Canada (Fig. 1), for canola and spring wheat yield simulation. Basic information (including geographical position, climate, and soil) for these 10 locations is presented in Table 1. 


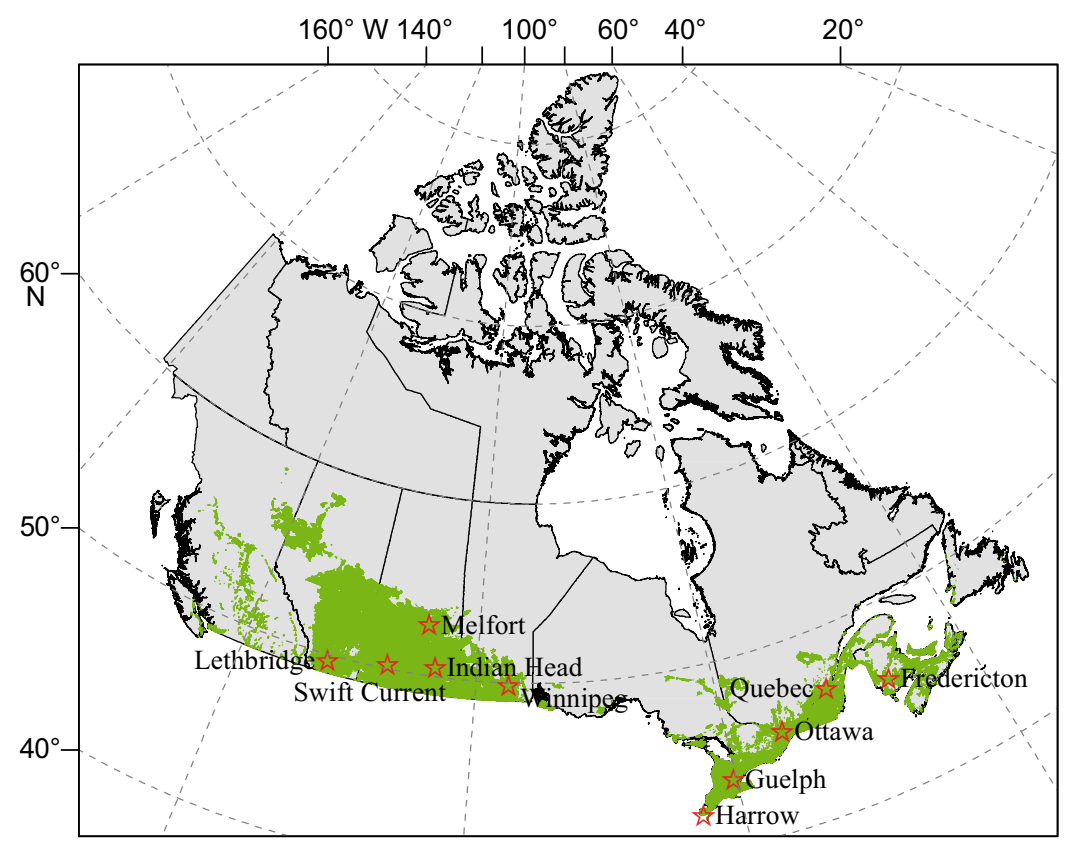

Fig. 1. Selected locations in the agricultural production areas (shaded in green) across Canada

Table 1. Site coordinates, soil texture (clay and silt percentages), and climate normals for precipitation and temperature for $10 \mathrm{se}-$ lected locations across Canada. $P_{\text {total }}$ and $T_{\text {mean }}$ represent average accumulated precipitation and mean temperature, respectively, in the crop growing season (May 1 to Aug 31) for the period 1971-2000

\begin{tabular}{|lcccccc|}
\hline Site & $\begin{array}{c}\text { Latitude } \\
\left({ }^{\circ} \mathrm{N}\right)\end{array}$ & $\begin{array}{c}\text { Longitude } \\
\left({ }^{\circ} \mathrm{W}\right)\end{array}$ & $\begin{array}{c}\text { Clay } \\
(\%)\end{array}$ & $\begin{array}{c}\text { Silt } \\
(\%)\end{array}$ & $\begin{array}{c}P_{\text {total }} \\
(\mathrm{mm})\end{array}$ & $\begin{array}{c}T_{\text {mean }} \\
\left({ }^{\circ} \mathrm{C}\right)\end{array}$ \\
\hline $\begin{array}{l}\text { Lethbridge } \\
\text { Swift Current }\end{array}$ & 49.70 & 112.78 & 23 & 36 & 209.8 & 15.6 \\
Indian Head & 50.27 & 107.73 & 20 & 45 & 207.3 & 15.6 \\
Melfort & 52.82 & 103.65 & 55 & 43 & 256.1 & 15.8 \\
Winnipeg & 49.90 & 97.69 & 50 & 40 & 242.7 & 15.0 \\
Guelph & 43.55 & 80.22 & 12 & 53 & 349.3 & 16.9 \\
Ottawa & 45.38 & 75.72 & 43 & 40 & 348.9 & 18.1 \\
Harrow & 42.03 & 82.90 & 23 & 55 & 319.7 & 19.6 \\
Quebec & 46.79 & 71.39 & 37 & 44 & 445.2 & 16.2 \\
Fredericton & 45.92 & 66.62 & 10 & 20 & 366.2 & 16.4 \\
\hline
\end{tabular}

\subsection{Climate data}

Observed daily maximum temperature $\left(T_{\max }\right)$, daily minimum temperature $\left(T_{\min }\right)$, and daily precipitation (Prec) for 1971-2000 at the 10 locations were obtained from Environment and Climate Change Canada's National Climate Data and Information Archive. Values of daily solar radiation (Rad) were extracted from a high-resolution global dataset of meteorological forcings for land surface modelling (Sheffield et al. 2006) because Rad was not observed at most locations.
Bias-corrected and downscaled GCM data including daily $T_{\max }, T_{\min }, P_{1}$, and Rad (GCM scenarios) were used to drive the crop models and calculate the climate change factors used in stochastic weather generation. Daily outputs of $T_{\max }, T_{\min }$, Prec, and Rad from the 20 GCMs in the CMIP5 archive (Table 2) for the baseline period 1971-2000 and 2 projection periods, 2040-2069 and 2070-2099, under the forcing scenarios RCP4.5 and RCP8.5 were used in this study. RCP4.5 and RCP8.5 represent medium-low and high emission scenarios with a radiative forcing of 4.5 and $8.5 \mathrm{~W} \mathrm{~m}^{-2}$ at the end of the 21st century, respectively (IPCC 2014).

Observed data were used to bias correct and downscale the GCM simulations as well as for calibrating the LARS-WG site parameters. Bias correction/downscaling is performed using a multivariate form of quantile mapping - multivariate bias correction using $N$-dimensional probability distribution transfer (MBCn) (Kirchmeier-Young et al. 2017, Cannon 2018) - that, first, corrects GCM marginal distributions and the multivariate dependence structure between sites and variables to match historical observations and, second, preserves GCM-projected changes in quantiles in future periods. Specifically, $T_{\max }, T_{\min }$, Prec, and Rad from each GCM at each location are corrected simultaneously, using the 1971-2000 observational period for calibration. The MBCn bias correction algorithm (ver. 0.10-1, https://cran.r-project.org/ package $=\mathrm{MBC} ; \mathrm{R}$ ver. 3.3.2, www.r-project.org) is applied over $30 \mathrm{yr}$ sliding windows on concatenated historical (1950-2005) and RCP scenario (2006-2100) periods. In each window, the central decade is replaced, the window is slid forward 1 decade, etc., until the end of the projection period is reached. To ensure an unbiased seasonal cycle, adjustments are applied over data that have been pooled over 33 day-of-year sliding blocks - the central $11 \mathrm{~d}$ are replaced, the block is slid $11 \mathrm{~d}$, etc. To ensure that corrected values of $T_{\max }$ exceed $T_{\min }$ on all days, MBCn is applied to the diurnal temperature range $\left(T_{\max }-T_{\min }\right)$ and approximate mean temperature ([ $\left.\left.T_{\min }+T_{\max }\right] / 2\right)$ variables. Outside of the 19712000 calibration period, changes in corrected quantiles are constrained to match those in the raw climate model simulations (i.e. the adjustments made by $\mathrm{MBCn}$ are change preserving on a quantile-by-quantile basis) (Cannon et al. 2015). After bias correction, 
Table 2. Basic information for the 20 global climate models in CMIP5 used in this study

\begin{tabular}{|c|c|c|c|}
\hline No. & Model & $\begin{array}{l}\text { Resolution } \\
\text { (Lon. } \times \text { Lat.) }\end{array}$ & Institute and country \\
\hline $\begin{array}{l}1 \\
2\end{array}$ & $\begin{array}{l}\text { bcc-csm1-1-m } \\
\text { bcc-csm1-1 }\end{array}$ & $\begin{aligned} & 1.125^{\circ} \times 1.125^{\circ} \\
& 2.8^{\circ} \times 2.8^{\circ}\end{aligned}$ & Beijing Climate Center, China Meteorological Administration, PR China \\
\hline 3 & BNU-ESM & $2.8^{\circ} \times 2.8^{\circ}$ & $\begin{array}{l}\text { College of Global Change and Earth System Science, Beijing Normal } \\
\text { University, PR China }\end{array}$ \\
\hline 4 & CanESM2 & $2.8^{\circ} \times 2.8^{\circ}$ & Canada Centre for Climate Modelling and Analysis, Canada \\
\hline 5 & CNRM-CM5 & $1.4^{\circ} \times 1.4^{\circ}$ & $\begin{array}{l}\text { Centre National de Recherches Météorologiques and Centre Européen } \\
\text { de Recherche et Formation Avancée en Calcul Scientifique, France }\end{array}$ \\
\hline 6 & CSIRO-Mk3-6-0 & $1.9^{\circ} \times 1.9^{\circ}$ & $\begin{array}{l}\text { Commonwealth Scientific and Industrial Research Organization and } \\
\text { Queensland Climate Change Centre of Excellence, Australia }\end{array}$ \\
\hline 7 & FGOALS-g2 & $1.875^{\circ} \times 1.25^{\circ}$ & $\begin{array}{l}\text { Sate Key Laboratory of Numerical Modeling for Atmospheric Sciences } \\
\text { and Geophysical Fluid Dynamics, Institute of Atmospheric Physics, } \\
\text { Chinese Academy of Sciences, and Center for Earth System Science, } \\
\text { Tsinghua University, PR China }\end{array}$ \\
\hline $\begin{array}{l}8 \\
9\end{array}$ & $\begin{array}{l}\text { GFDL-ESM2G } \\
\text { GFDL-ESM2M }\end{array}$ & $\begin{array}{l}2.5^{\circ} \times 2.0^{\circ} \\
2.5^{\circ} \times 2.0^{\circ}\end{array}$ & Geophysical Fluid Dynamics Laboratory, NOAA, USA \\
\hline 10 & HadGEM2-AO & $1.875^{\circ} \times 1.25^{\circ}$ & $\begin{array}{l}\text { National Institute of Meteorological Research, Korea Meteorological } \\
\text { Administration, Korea, and Met Office Hadley Centre, UK }\end{array}$ \\
\hline 11 & HadGEM2-ES & $1.875^{\circ} \times 1.25^{\circ}$ & Met Office Hadley Centre, UK \\
\hline $\begin{array}{l}12 \\
13\end{array}$ & $\begin{array}{l}\text { IPSL-CM5A-LR } \\
\text { IPSL-CM5A-MR }\end{array}$ & $\begin{array}{l}3.75^{\circ} \times 1.875^{\circ} \\
2.5^{\circ} \times 1.25^{\circ}\end{array}$ & Institut Pierre Simon Laplace, France \\
\hline 14 & MIROC-ESM-CHEM & $2.8^{\circ} \times 2.8^{\circ}$ & Japan Agency for Marine-Earth Science and Technology, Atmosphere \\
\hline 15 & MIROC-ESM & $2.8^{\circ} \times 2.8^{\circ}$ & $\begin{array}{l}\text { and Ocean Research Institute (The University of Tokyo), and National } \\
\text { Institute for Environmental Studies, Japan }\end{array}$ \\
\hline 16 & MIROC5 & $1.4^{\circ} \times 1.4^{\circ}$ & $\begin{array}{l}\text { Atmosphere and Ocean Research Institute (The University of Tokyo), } \\
\text { National Institute for Environmental Studies, and Japan Agency for } \\
\text { Marine-Earth Science and Technology, Japan }\end{array}$ \\
\hline 17 & MPI-ESM-LR & $1.875^{\circ} \times 1.875^{\circ}$ & Max Planck Institute for Meteorology, Germany \\
\hline 18 & MPI-ESM-MR & $1.875^{\circ} \times 1.875^{\circ}$ & \\
\hline 19 & MRI-CGCM3 & $1.125^{\circ} \times 1.125^{\circ}$ & Meteorological Research Institute, Japan \\
\hline 20 & NorESM1-M & $2.5^{\circ} \times 1.9^{\circ}$ & Norwegian Climate Centre, Norway \\
\hline
\end{tabular}

diurnal temperature range and approximate mean temperature are transformed back to $T_{\max }$ and $T_{\min }$.

\subsection{Stochastic weather generation}

LARS-WG was used to generate the En-WG and WG scenarios. LARS-WG is a stochastic weather generator based on the series approach (Semenov \& Barrow 1997, Semenov \& Stratonovitch 2010), in comparison with the Richardson-type stochastic weather generators that use either first- or higher-order Markov chains (Richardson 1981). It utilizes observed daily weather data of a given site to compute a set of parameters for probability distributions of weather variables as well as correlations between them (Semenov \& Stratonovitch 2010). This set of parameters is used to generate synthetic weather time se- ries with statistical characteristics corresponding to the observed datasets. To generate future weather data, the LARS-WG parameters from historical climate data are perturbed by a scenario of climate change in terms of change factors. LARS-WG is available from https://sites.google.com/view/lars-wg/.

Bias-corrected and downscaled daily $T_{\max }, T_{\min }$ and Prec from $20 \mathrm{GCMs}$ for the baseline period (1971-2000) and 2 relevant future periods (20402069 and 2070-2099) under RCP4.5 and RCP8.5 at 10 locations across Canada were used to calculate change factors. For each GCM at each location in the baseline period and the 2 future periods under both emission scenarios, monthly mean $T_{\max }$ and $T_{\min }$, monthly mean Prec, monthly mean duration of wet and dry spells, and SDs of daily mean temperature were calculated. Change factors of these climate statistics for the 2 future periods with respect to the 
baseline period were then calculated for each GCM at each location. Differences were calculated for monthly mean $T_{\max }$ and $T_{\min }$, while ratios were calculated for the other statistics. After that, 20 sets of change factors corresponding to the 20 GCMs were obtained. Each set includes 4 scenarios, 2 future periods under 2 RCPs for each location. They were used to perturb the parameters in LARS-WG for generating 300 yr long daily site-specific weather data representing the climate conditions of 2040-2069 and 2070-2099 under RCP4.5 and RCP8.5 for each GCM (WG scenarios). Ensemble means of the change factors from the $20 \mathrm{GCMs}$ were used to generate the single En-WG scenarios, i.e. 4 En-WG scenarios for each location under 2 RCPs for 2 future periods. Daily Rad data in the WG and En-WG scenarios were estimated using daily temperature and precipitation data, with location-specific coefficients calibrated with historical observed data (Qian et al. 2019b).

\subsection{Crop simulation}

The CSM-CERES-wheat model and the CSMCROPGRO-canola model included in DSSAT ver. 4.7 were used to simulate crop yields for spring wheat and canola in this study. Crop models in DSSAT have been widely used in climate change impact studies around the world (e.g. He et al. 2018, Cammarano et al. 2020, Hussain et al. 2020, Ye et al. 2020). Furthermore, these 2 models have been calibrated and evaluated with field experimental data in Canada (Jing et al. 2016, 2017) and used to assess climate change impacts (Qian et al. 2016a, 2018, 2019a). Climate data, soil information, crop cultivar parameters, and crop management practices are required as inputs to the crop models. Soil data for each site were obtained from the Canadian Soil Information System, Soil Landscapes of Canada, ver. 3.2 (Soil Landscapes of Canada Working Group 2010). Spring wheat cultivar AC Barrie and canola cultivar InVigor 5440 calibrated in Canada by Jing et al. $(2016,2017)$ were used to simulate crop yields as continuous spring wheat and canola. All simulations included the direct effects of elevated atmospheric $\mathrm{CO}_{2}$ concentration. Planting date in simulations for both spring wheat and canola was May 15 for the baseline period 19712000 and May 8 for the future periods. A fixed planting date was used for simplicity in crop simulations, as planting date is considered a crop management practice that can vary from year to year and by location. Crops were harvested automatically at physiological maturity in all the simulations. Although $\mathrm{N}$ fertilizer applications are an important agronomic management practice for rainfed crop production, we simulated only the water-limited yield $\left(Y_{\mathrm{w}}\right)$ of crops grown without $\mathrm{N}$ stress to emphasize the climate impacts. Soil texture may have significant impacts on crop growth and yield in the simulations of $Y_{\mathrm{w}}$ therefore, simulated crop yields at the selected locations can be different if other soils are used.

\subsection{Quantitative evaluation}

To quantitatively assess how close simulated crop yields using En-WG scenarios are to the ensemble means of simulated yields using multiple climate scenarios (WG scenarios), we compared them with the yields from all (i.e. 20 in this study) or any one of the WG scenarios using 2 statistical measures. Closeness is defined as the absolute value of the difference between the long-term mean of simulated yields using En-WG scenarios $\left(Y_{\text {En }}\right)$ and ensemble mean yields $\left(Y_{\mathrm{m}}\right)$, i.e. $\mid Y_{\mathrm{En}}-Y_{\mathrm{m}} \mathrm{l}_{;} Y_{\mathrm{m}}$ is the average of the long-term means of simulated yields $\left(Y_{i}, i=1,20\right)$ using the 20 WG scenarios. We defined relative difference (RD) in Eq. (1). We used the proportion as an estimate of the probability $(p)$ of the WG scenario based on a randomly chosen GCM from the 20 $\operatorname{GCMs}\left(Y_{i}, i=1,20\right)$, that may have a smaller difference to the ensemble mean $\left(Y_{\mathrm{m}}\right)$ than En-WG $\left(Y_{\mathrm{En}}\right)$, i.e. $\left|Y_{i}-Y_{\mathrm{m}}\right|<\left|Y_{\text {En }}-Y_{\mathrm{m}}\right|, N_{\mathrm{s}}$ is the total number of GCMs with a smaller difference, in Eq. (2). Smaller values of these indicators indicate better performance of the En-WG scenario at reproducing the ensemble mean. The values of these indicators can be averaged across locations for evaluating the overall performance.

$$
\begin{gathered}
\mathrm{RD}=\frac{\left|Y_{\text {En }}-Y_{\mathrm{m}}\right|}{Y_{\mathrm{m}}} \times 100 \% \\
N_{s}=\sum_{i=1}^{20}\left(1, \text { if }\left|Y_{i}-Y_{\mathrm{m}}\right|<Y_{\text {En }}-Y_{\mathrm{m}} \mid ; 0, \text { otherwise }\right) \\
p=\frac{N_{s}}{20}
\end{gathered}
$$

\section{RESULTS}

The long-term means of canola yields and spring wheat yields simulated using En-WG scenarios were compared with those using 20 WG scenarios for 2 future periods (2040-2069 and 2070-2099) under RCP4.5 and RCP8.5 in Figs. 2 \& 3, respectively. As shown, the ranges of the simulated yields across the 
20 WG scenarios are generally smaller in eastern Canada (i.e. Guelph, Ottawa, Harrow, Quebec, and Fredericton) than in the Canadian Prairies (i.e. Lethbridge, Swift Current, Indian Head, Melfort, and Winnipeg) for both canola and spring wheat but especially for spring wheat. This could be reflecting the facts that crop yields on the Canadian Prairies are limited by water stress and large uncertainties are often present in the projections of precipitation in
GCMs. Smaller ranges across the 20 WG scenarios at some locations may lead to a biased impression for the performance of the En-WG scenarios, as all individual members are relatively close to the ensemble means of the 20 WG scenarios when they are compared to locations with larger ranges. Interestingly, as observed in Figs. $2 \& 3$ the canola/spring wheat yields simulated using the En-WG scenarios are close to the ensemble means of the canola/spring

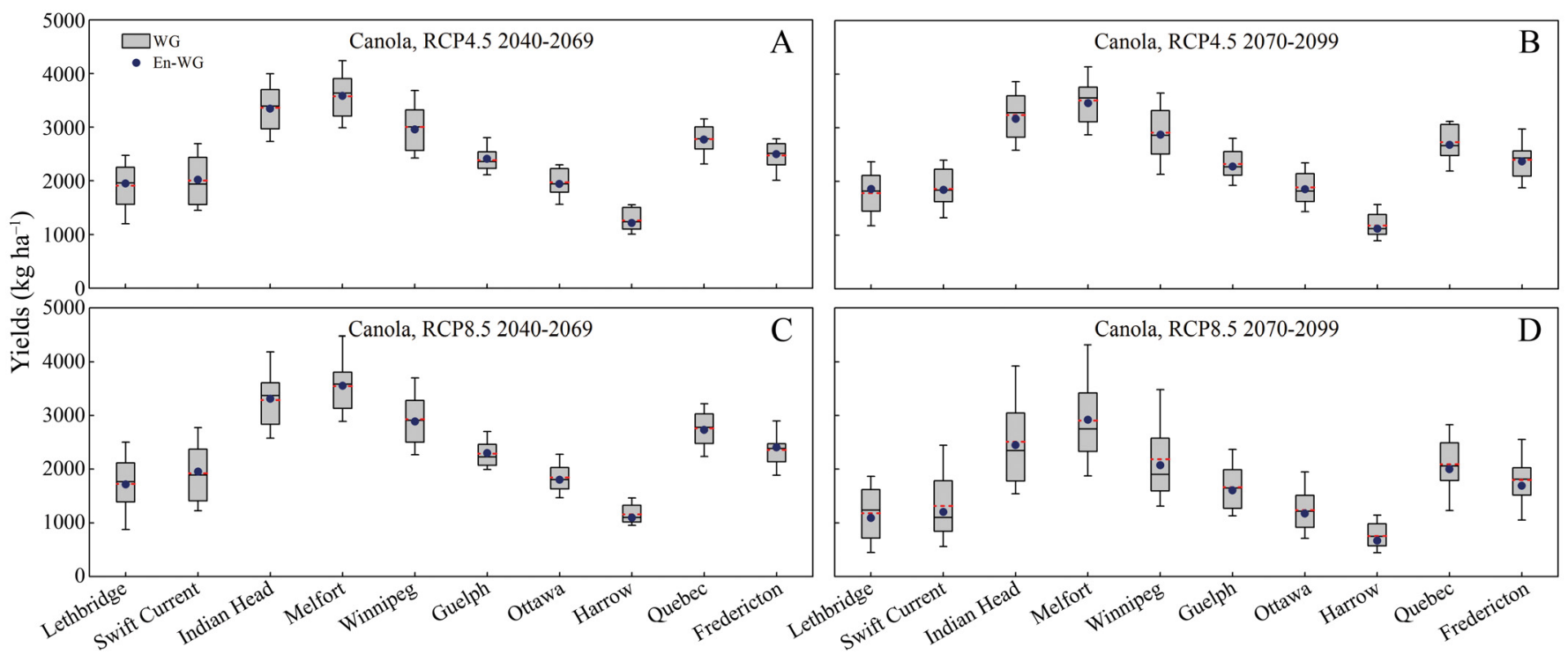

Fig. 2. Simulated canola yields in 2 future periods, 2040-2069 and 2070-2099, under RCP4.5 and RCP8.5 at 10 locations across Canada. Boxplots show the 10th, 25th, 50th, 75th, and 90th percentiles of simulated yields across 20 WG scenarios. Red dashes represent the means of yields derived from 20 WG scenarios; solid circles are the yields simulated with En-WG scenarios

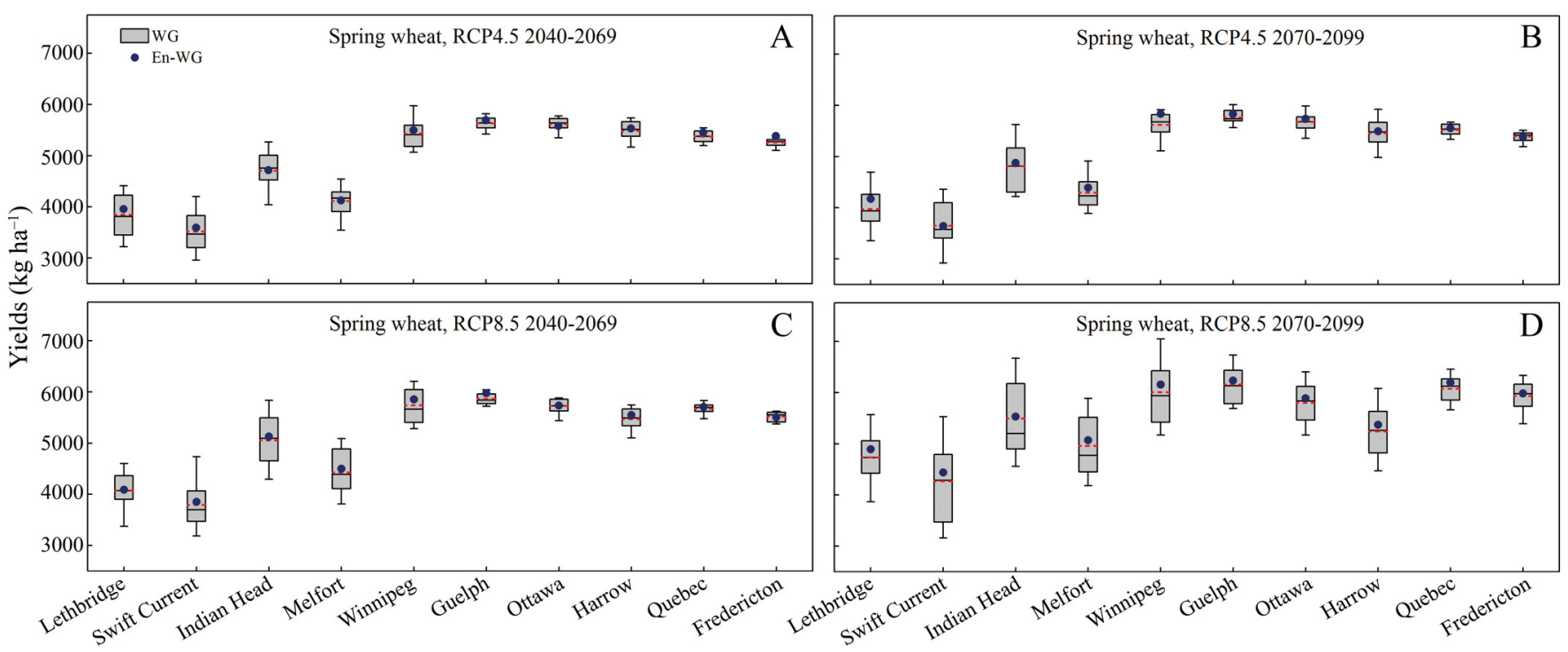

Fig. 3. Simulated spring wheat yields in 2 future periods, 2040-2069 and 2070-2099, under RCP4.5 and RCP8.5 at 10 locations across Canada. Symbols are as described in Fig. 2 
wheat yields simulated using the 20 WG scenarios. This is true across most of the 10 locations and all 4 future scenarios.

Two statistical indicators for quantitatively assessing the performance of the single En-WG scenarios in terms of reproducing the ensemble means of yields derived from multiple WG scenarios, RD and $\mathrm{p}$, were calculated for each location for the future periods 2040-2069 and 2070-2099 under RCP4.5 and RCP8.5. The results are shown in Table 3 for canola and Table 4 for spring wheat. In Table 3, all values for $\mathrm{p}$ are smaller than 0.3 , and most of them are smaller than 0.05, indicating that the single En-WG scenarios, in most cases, outperformed a randomly selected GCM for reproducing the ensemble means of yields. For Harrow in 2070-2099 under RCP8.5, the simulated canola yield using the En-WG scenario

Table 3. Relative difference (RD, \%) and probability $(p)$ for assessing the performance of En-WG scenarios for canola yield simulations

\begin{tabular}{|c|c|c|c|c|c|c|c|c|}
\hline & \multicolumn{4}{|c|}{$-\mathrm{RCP} 4.5-$} & \multicolumn{4}{|c|}{ RCP8.5 } \\
\hline & \multicolumn{2}{|c|}{$2040-2069$} & \multicolumn{2}{|c|}{ 2070-2099 } & \multicolumn{2}{|c|}{ 2040-2069 } & \multicolumn{2}{|c|}{ 2070-2099 } \\
\hline & $\mathrm{RD}$ & $p$ & $\mathrm{RD}$ & $p$ & $\mathrm{RD}$ & $p$ & $\mathrm{RD}$ & $p$ \\
\hline Lethbridge & 2.1 & 0.10 & 4.4 & 0.10 & 0.7 & 0.00 & 7.3 & 0.15 \\
\hline Swift Current & 0.7 & 0.00 & 1.0 & 0.00 & 1.7 & 0.00 & 8.5 & 0.05 \\
\hline Indian Head & 0.5 & 0.05 & 2.2 & 0.05 & 0.7 & 0.00 & 2.7 & 0.05 \\
\hline Melfort & 0.1 & 0.00 & 1.5 & 0.00 & 0.2 & 0.00 & 0.5 & 0.00 \\
\hline Winnipeg & 1.6 & 0.05 & 1.3 & 0.00 & 1.4 & 0.05 & 5.1 & 0.05 \\
\hline Guelph & 1.2 & 0.05 & 2.0 & 0.00 & 0.4 & 0.00 & 3.7 & 0.15 \\
\hline Ottawa & 1.6 & 0.05 & 1.9 & 0.00 & 2.5 & 0.10 & 5.1 & 0.10 \\
\hline Harrow & 3.7 & 0.15 & 5.0 & 0.10 & 5.2 & 0.20 & 11.6 & 0.20 \\
\hline Quebec & 0.4 & 0.10 & 1.9 & 0.00 & 1.0 & 0.05 & 4.5 & 0.15 \\
\hline Fredericton & 0.8 & 0.15 & 1.1 & 0.05 & 1.9 & 0.15 & 5.9 & 0.30 \\
\hline Average & 1.3 & 0.07 & 2.2 & 0.03 & 1.6 & 0.06 & 5.5 & 0.12 \\
\hline
\end{tabular}

Table 4. Relative difference (RD, \%) and probability $(p)$ for assessing the performance of En-WG scenarios for spring wheat yield simulations

\begin{tabular}{|c|c|c|c|c|c|c|c|c|}
\hline & \multicolumn{4}{|c|}{$-\mathrm{RCP} 4.5-$} & \multicolumn{4}{|c|}{$\longrightarrow$ RCP8.5 } \\
\hline & \multicolumn{2}{|c|}{ 2040-2069 } & \multicolumn{2}{|c|}{ 2070-2099 } & \multicolumn{2}{|c|}{$2040-2069$} & \multicolumn{2}{|c|}{ 2070-2099 } \\
\hline & $\mathrm{RD}$ & $p$ & $\mathrm{RD}$ & $p$ & $\mathrm{RD}$ & $p$ & $\mathrm{RD}$ & $p$ \\
\hline Lethbridge & 2.8 & 0.20 & 5.0 & 0.45 & 0.3 & 0.10 & 3.3 & 0.30 \\
\hline Swift Current & 2.1 & 0.15 & 0.1 & 0.00 & 1.5 & 0.05 & 4.0 & 0.25 \\
\hline Indian Head & 0.3 & 0.00 & 1.3 & 0.05 & 1.5 & 0.05 & 0.7 & 0.05 \\
\hline Melfort & 0.3 & 0.00 & 2.3 & 0.15 & 1.6 & 0.15 & 2.2 & 0.10 \\
\hline Winnipeg & 1.2 & 0.20 & 3.8 & 0.60 & 2.0 & 0.05 & 2.5 & 0.25 \\
\hline Guelph & 1.1 & 0.40 & 1.2 & 0.40 & 1.9 & 0.60 & 1.2 & 0.10 \\
\hline Ottawa & 0.6 & 0.25 & 1.2 & 0.40 & 0.1 & 0.00 & 1.5 & 0.15 \\
\hline Harrow & 0.8 & 0.15 & 0.7 & 0.15 & 1.5 & 0.15 & 2.4 & 0.10 \\
\hline Quebec & 1.5 & 0.45 & 0.6 & 0.15 & 0.6 & 0.30 & 2.0 & 0.20 \\
\hline Fredericton & 2.5 & 0.80 & 0.1 & 0.00 & 0.3 & 0.05 & 0.8 & 0.20 \\
\hline Average & 1.3 & 0.26 & 1.6 & 0.24 & 1.1 & 0.15 & 2.1 & 0.17 \\
\hline
\end{tabular}

shows the biggest relative difference from the ensemble mean yield, with an RD value of $11.6 \%$. The $p$ value is 0.20 , which indicates that the En-WG scenario would still be more likely to outperform the cases using $1 \mathrm{GCM}$. In other cases, the RDs are all less than $10 \%$ and mostly less than $5 \%$, showing small differences between the En-WG simulated canola yields and the ensemble means of canola yields derived from the $20 \mathrm{WG}$ scenarios. The overall performances of the single En-WG scenarios across the 10 locations are satisfactory in the 2 future periods (2040-2069 and 2070-2099) under both RCP4.5 and RCP8.5.

In Table 4, all values for RD are less than $5 \%$. The small RD values indicate very small differences between spring wheat yields simulated using the En-WG scenarios and the ensemble means of spring wheat yields simulated using the 20 WG scenarios. For the other indicator, p, except for Fredericton in 20402069 under RCP4.5 $(p=0.79)$, Winnipeg in 2070-2099 under RCP4.5 $(p=$ $0.60)$, and Guelph in 2040-2069 under RCP8.5 $(p=0.60)$, all $p$ values are under 0.5 and mostly under 0.25 , indicating that the ensemble mean using the En-WG scenarios is more likely than not to outperform a randomly selected WG scenario. However, even in the 3 cases where the En-WG scenarios are less likely to outperform a randomly selected GCM, the RDs between En-WG simulated spring wheat yields and the ensemble means of yields simulated with the 20 WG scenarios are very small $(2.5,3.8$, and $1.9 \%$, respectively), reflecting good performance of the single En-WG scenarios. In fact, the ranges of the simulated yields across the 20 WG scenarios are often relatively small in these 3 cases; hence, all ensemble members are close to the ensemble mean, which results in a large $p$ in these 3 cases. The average values for RD across the 10 locations in 2 future periods under 2 RCPs are all less than $3 \%$, and the average values for $\mathrm{p}$ are all smaller than 0.30 , implying satisfactory overall performance of the En-WG scenarios for producing crop yields close to the ensemble mean yields based on the 20 WG scenarios. 


\section{DISCUSSION}

In this study, a stochastic weather generator, LARSWG, was used to develop future climate scenarios (i.e. WG and En-WG scenarios) from multiple GCMs under 2 forcing scenarios, RCP4.5 and RCP8.5. Stochastic weather generators have attracted attention in the past decades as a convenient tool for producing daily climate scenarios in climate change impact studies (Qian et al. 2005, 2010, Kilsby et al. 2007). Qian et al. (2011) compared simulated crop yields with observed and synthetic weather data generated by a stochastic weather generator. They found that reliable crop yield estimates could be obtained by using the stochastic weather data to drive DSSAT crop growth models at the Canadian locations in their study. However, stochastic weather generators suffer from the problem known as overdispersion, i.e. they underestimate the interannual variability of climate (Katz \& Parlange 1998, Qian et al. 2004, Chen \& Brissette 2014). To represent the interannual variability of climate in a $30 \mathrm{yr}$ period, we calculated the SD of mean temperature $\left(T_{\text {mean }}\right)$ and the coefficient of variation of accumulated precipitation $\left(P_{\text {total }}\right)$ in the crop growing season (May 1 to Aug 31) based on $300 \mathrm{yr}$ long climate data from the 20 WG scenarios. The interannual variability of $T_{\text {mean }}$ and $P_{\text {total }}$ in the growing season derived from 20 bias-corrected and downscaled GCMs (GCM scenarios) was also calculated for a comparison. Fig. 4 shows the results in 20702099 under RCP8.5 for 2 locations as examples, Swift Current on the Canadian Prairies and Ottawa in eastern Canada. As observed in Fig. 4, the interannual variability of $T_{\text {mean }}$ and $P_{\text {total }}$ in the crop growing season derived from GCM scenarios is notably larger than that derived from WG scenarios. The bias correction of GCMs, used previously in Qian et al. (2019a, 2020), did not change the relative year-to-year variations of climate (not shown). However, LARS-WG does not consider potential changes in climate variability from year to year (Prudhomme et al. 2002), in addition to the common overdispersion issue for the baseline climate in stochastic weather generation, and thus underestimates interannual variability.

Due to the underestimation of the interannual variability of climate in stochastic weather generation by LARS-WG, it is very likely that the interannual variability of crop yields simulated using WG scenarios will also be underestimated. Thus, we compared the interannual variability of crop yields simulated using GCM scenarios with that simulated using WG scenarios. Here we only presented the results for canola yield simulations in 2070-2099 under RCP8.5 (Fig. 5),
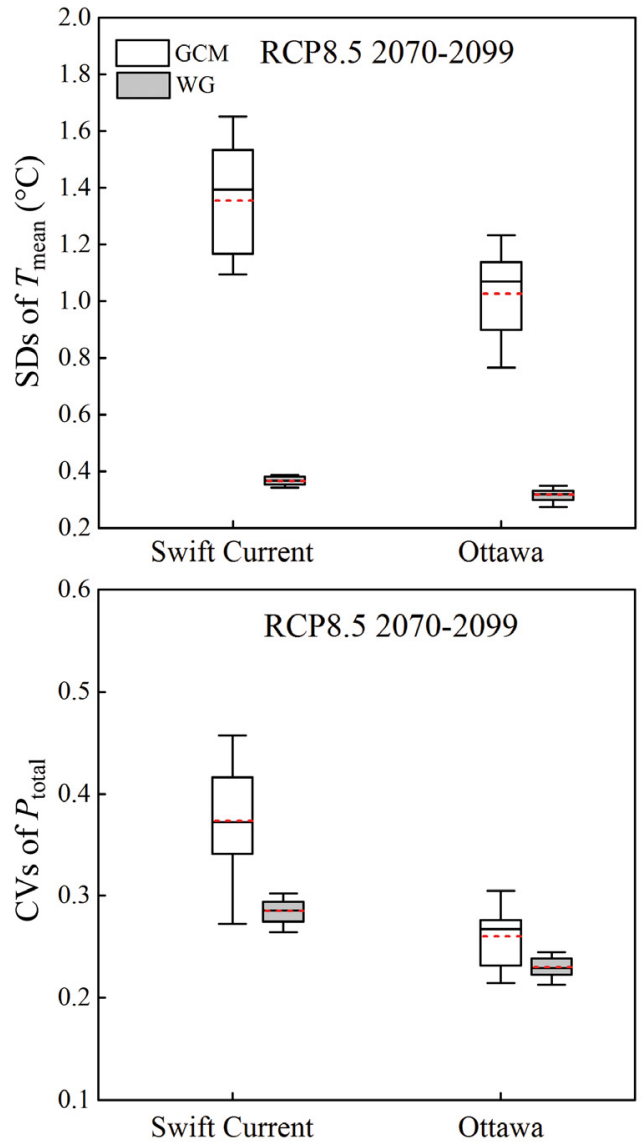

Fig. 4. (A) SDs of mean temperature $\left(T_{\text {mean }}\right)$ and (B) coefficients of variation $(\mathrm{CVs})$ of accumulated precipitation $\left(P_{\text {total }}\right)$ in the crop growing season (May 1-Aug 31) in 2070-2099 under RCP8.5 at 2 selected locations (i.e. Swift Current and Ottawa). Boxplots show the 10th, 25th, 50th, 75th, and 90th percentiles of SDs/CVs across $20 \mathrm{GCM} / W G$ scenarios. Red dashes represent the means of SDs/CVs derived from 20 GCM/WG scenarios

as those from all other cases are similar. Although ensemble-mean yields derived from WG and GCM scenarios are relatively close for most locations (Figs. S1 \& S2 in the Supplement at www.int-res.com/articles/ suppl/c083p161_supp.pdf), the interannual variability (represented by SD) of crop yields derived from WG scenarios is always lower than that derived from GCM scenarios, which is consistent with what is seen in the WG-generated climate.

Our results support the need for corrections or improvements in stochastic weather generation algorithms, such as LARS-WG used in this study, to remedy the underestimation of interannual climate variability, as several previous studies do (Semenov et al. 1998, Mavromatis \& Hansen 2001, Qian et al. 2004). Efforts have been made to reduce overdispersion in stochastic weather generators (Wang \& Nathan 2007, Kim et al. 2012). For example, Kim et al. (2012) cou- 


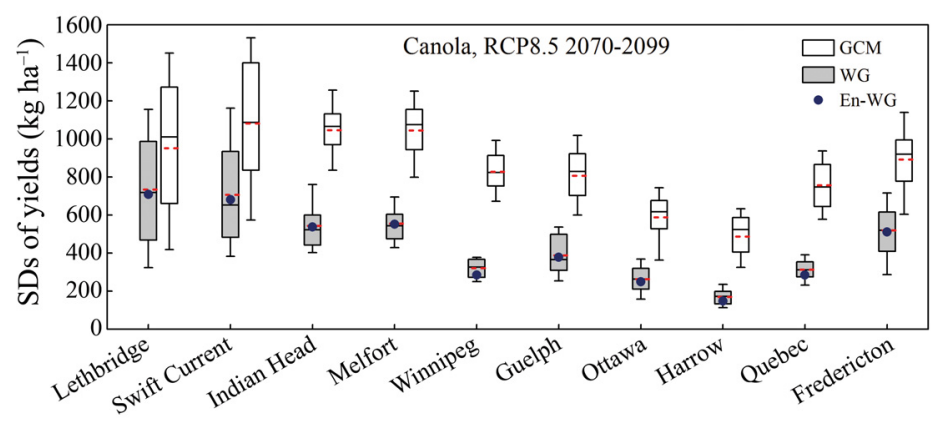

Fig. 5. SDs of simulated canola yields in 2070-2099 under RCP8.5 at 10 locations across Canada. Boxplots show the 10th, 25th, 50th, 75th, and 90th percentiles of SDs of yields across 20 GCM/WG scenarios. Red dashes represent the means of SDs derived from 20 GCM/WG scenarios; solid circles are the SDs of yields driven by En-WG scenarios ering the large amount of time needed to run process-based crop models driven by a large number of climate scenarios, an algorithm for selecting a limited number of climate scenarios from a multi-model ensemble will be useful in crop yield projections to account for uncertainty. One of the possible options would be to select a small number of GCMs based on their climatic sensitivity representative to the full CMIP5 ensemble (Semenov \& Stratonovitch 2015) using a procedure such as the Katsavounidis-Kuo-Zhang algorithm (Katsavounidis et al. 1994), which can be applied for recursively selecting members that best span the spread of an ensemble (Cannon 2015). Using estimates of the ranges based on a small subset of GCMs in combination with the ensemble means derived using the approach proposed in this study could effectively meet the demand of end users. However, further studies are required to evaluate the effectiveness of such selection methods on covering the ranges of full ensembles for crop yield projections.

Nevertheless, more studies may be needed to better understand the potential of the proposed approach for using ensemble-mean climate scenarios in climate change impact studies with multi-GCM ensembles and to explore whether its results could be reproduced well for different crop types, crop models, weather generators, and GCM ensembles, although 2 different spring crops and 2 structurally different crop models were used in this study.

\section{CONCLUSIONS}

In this study, we developed single ensemble-mean climate scenarios (En-WG) for 2 future periods (20402069 and 2070-2099) under 2 RCPs (RCP4.5 and RCP8.5) at 10 locations across Canada using LARSWG based on the ensemble means of climate change factors estimated from 20 CMIP5 GCMs. We compared simulated crop yields using En-WG scenarios with the ensemble means of simulated yields using 20 climate scenarios (WG scenarios) generated by LARS-WG based on 20 individual GCMs. We introduced 2 statistical measures, RD and p, of a randomly chosen GCM outperforming the En-WG scenario for reproducing the ensemble mean estimate. The simulated crop yields using the En-WG scenarios were close to the ensemble means of the simulated crop yields using the 20 WG scenarios. Moreover, using single En-WG scenarios in crop yield projections often outperformed using individual WG scenarios. quired by stakeholders for decision making. Consid- 
However, climate scenarios generated by LARS-WG usually resulted in the underestimation of interannual variability in the simulated crop yields, which is common for many weather generators. The En-WG scenarios have the potential of efficiently estimating the ensemble means of future crop yield projections in a multi-GCM ensemble when a stochastic approach is applied to each of the individual GCMs, in terms of much less time (only $5 \%$ of a $20 \mathrm{GCM}$ ensemble) for running simulations and a reasonable accuracy (approximately a $2 \%$ error on average).

Acknowledgements. This study is partly supported by Agriculture and Agri-Food Canada (AAFC) under the Interdepartmental Research Initiative in Agriculture (Project J002303). D.M. is supported by the China Scholarship Council under the AAFC-MOE Joint PhD Program for her research participation at AAFC. Rothamsted Research receives grantaided support from the Biotechnology and Biological Sciences Research Council (BBSRC) through Designing Future Wheat (BB/P016855/1) and Achieving Sustainable Agricultural Systems (NE/N018125/1) jointly funded with NERC. The authors are indebted to 2 anonymous reviewers and the editor for their constructive comments leading to the improvement of this manuscript.

\section{LITERATURE CITED}

Al Samouly A, Luong CN, Li Z, Smith S, Baetz B, Ghaith M (2018) Performance of multi-model ensembles for the simulation of temperature variability over Ontario, Canada. Environ Earth Sci 77:524

Cammarano D, Valdivia RO, Beletse YG, Durand W and others (2020) Integrated assessment of climate change impacts on crop productivity and income of commercial maize farms in northeast South Africa. Food Secur 12: $659-678$

Cannon AJ (2015) Selecting GCM scenarios that span the range of changes in a multimodel ensemble: application to CMIP5 climate extremes indices. J Clim 28:1260-1267

* Cannon AJ (2018) Multivariate quantile mapping bias correction: an $\mathrm{N}$-dimensional probability density function transform for climate model simulations of multiple variables. Clim Dyn 50:31-49

Cannon AJ, Sobie SR, Murdock TQ (2015) Bias correction of GCM precipitation by quantile mapping: How well do methods preserve changes in quantiles and extremes? J Clim 28:6938-6959

Challinor AJ, Müller C, Asseng S, Deva C and others (2018) Improving the use of crop models for risk assessment and climate change adaptation. Agric Syst 159:296-306

* Chen J, Brissette FP (2014) Comparison of five stochastic weather generators in simulating daily precipitation and temperature for the Loess Plateau of China. Int J Climatol 34:3089-3105

* Gao C, Liu L, Ma D, He KQ, Xu YP (2019) Assessing responses of hydrological processes to climate change over the southeastern Tibetan Plateau based on resampling of future climate scenarios. Sci Total Environ 664: 737-752

He W, Yang JY, Qian B, Drury CF and others (2018) Climate change impacts on crop yield, soil water balance and nitrate leaching in the semiarid and humid regions of Canada. PLOS ONE 13:e0207370

Hoogenboom G, Porter CH, Shelia V, Boote KJ and others (2017) Decision support system for agrotechnology transfer (DSSAT) version 4.7. DSSAT Foundation, Gainesville, FL. https://DSSAT.net/

Hussain J, Khaliq T, Asseng S, Saeed U and others (2020) Climate change impacts and adaptations for wheat employing multiple climate and crop models in Pakistan. Clim Change 163:253-266

IPCC (2014) Summary for policymakers. In: Barros VR, Field CB, Dokken DJ, Mastrandrea MD and others (eds) Climate change 2014: impacts, adaptation and vulnerability. Part A: global and sectoral aspects. Working Group II contribution to the IPCC Fifth Assessment Report. Cambridge University Press, Cambridge and New York, NY

* Jing Q, Shang J, Qian B, Hoogenboom G and others (2016) Evaluation of the CSM-CROPGRO-canola model for simulating canola growth and yield at West Nipissing in eastern Canada. Agron J 108:575-584

Jing Q, Qian B, Shang J, Huffman T and others (2017) Assessing the options to improve regional wheat yield in eastern Canada using the CSM-CERES-wheat model. Agron J 109:510-523

Katsavounidis I, Kuo CCJ, Zhang Z (1994) A new initialization technique for generalized Lloyd iteration. IEEE Signal Process Lett 1:144-146

Katz RW, Parlange MB (1998) Overdispersion phenomenon in stochastic modeling of precipitation. J Clim 11:591-601

Kilsby CG, Jones PD, Burton A, Ford AC and others (2007) A daily weather generator for use in climate change studies. Environ Model Softw 22:1705-1719

Kim Y, Katz RW, Rajagopalan B, Podestá GP, Furrer EM (2012) Reducing overdispersion in stochastic weather generators using a generalized linear modeling approach. Clim Res 53:13-24

Kirchmeier-Young MC, Zwiers FW, Gillett NP, Cannon AJ (2017) Attributing extreme fire risk in western Canada to human emissions. Clim Change 144:365-379

Lutz AF, ter Maat HW, Biemans H, Shrestha AB, Wester P, Immerzeel WW (2016) Selecting representative climate models for climate change impact studies: an advanced envelope-based selection approach. Int J Climatol 36: 3988-4005

*Mavromatis T, Hansen JW (2001) Interannual variability characteristics and simulated crop response of four stochastic weather generators. Agric Meteorol 109:283-296

Moss RH, Edmonds JA, Hibbard KA, Manning MR and others (2010) The next generation of scenarios for climate change research and assessment. Nature 463:747-756

* Pierce DW, Barnett TP, Santer BD, Gleckler PJ (2009) Selecting global climate models for regional climate change studies. Proc Natl Acad Sci USA 106:8441-8446

* Prudhomme C, Reynard N, Crooks S (2002) Downscaling of global climate models for flood frequency analysis: Where are we now? Hydrol Processes 16:1137-1150

* Qian B, Gameda S, Hayhoe H, De Jong R, Bootsma A (2004) Comparison of LARS-WG and AAFC-WG stochastic weather generators for diverse Canadian climates. Clim Res 26:175-191

Qian B, Hayhoe H, Gameda S (2005) Evaluation of the stochastic weather generators LARS-WG and AAFC-WG for climate change impact studies. Clim Res 29:3-21

Qian B, Gameda S, De Jong R, Falloon P, Gornall J (2010) 
Comparing scenarios of Canadian daily climate extremes derived using a weather generator. Clim Res 41:131-149

Qian B, De Jong R, Yang J, Wang H, Gameda S (2011) Comparing simulated crop yields with observed and synthetic weather data. Agric Meteorol 151:1781-1791

Qian B, De Jong R, Huffman T, Wang H, Yang J (2016a) Projecting yield changes of spring wheat under future climate scenarios on the Canadian Prairies. Theor Appl Climatol 123:651-669

Qian B, Wang H, He Y, Liu J, De Jong R (2016b) Projecting spring wheat yield changes on the Canadian Prairies: effects of resolutions of a regional climate model and statistical processing. Int J Climatol 36:3492-3506

Qian B, Jing Q, Bélanger G, Shang J, Huffman T, Liu J, Hoogenboom G (2018) Simulated canola yield responses to climate change and adaptation in Canada. Agron J 110:133-146

Qian B, Zhang X, Smith W, Grant B and others (2019a) Climate change impacts on Canadian yields of spring wheat, canola and maize for global warming levels of $1.5^{\circ} \mathrm{C}$, $2.0^{\circ} \mathrm{C}, 2.5^{\circ} \mathrm{C}$ and $3.0^{\circ} \mathrm{C}$. Environ Res Lett $14: 074005$

* Qian B, Jing Q, Zhang X, Shang J and others (2019b) Adapting estimation methods of daily solar radiation for crop modelling applications in Canada. Can J Soil Sci 99: 533-547

Qian B, Jing Q, Smith W, Grant B, Cannon AJ, Zhang X (2020) Quantifying the uncertainty introduced by internal climate variability in projections of Canadian crop production. Environ Res Lett 15:074032

Richardson CW (1981) Stochastic simulation of daily precipitation, temperature, and solar radiation. Water Resour Res 17:182-190

Semenov MA, Barrow EM (1997) Use of a stochastic weather generator in the development of climate change scenarios. Clim Change 35:397-414

Semenov MA, Stratonovitch P (2010) Use of multi-model

Editorial responsibility: Davide Cammarano,

West Lafayette, Indiana, USA

Reviewed by: 2 anonymous referees ensembles from global climate models for assessment of climate change impacts. Clim Res 41:1-14

Semenov MA, Stratonovitch P (2015) Adapting wheat ideotypes for climate change: accounting for uncertainties in CMIP5 climate projections. Clim Res 65:123-139

Semenov MA, Brooks RJ, Barrow EM, Richardson CW (1998) Comparison of the WGEN and LARS-WG stochastic weather generators for diverse climates. Clim Res 10: 95-107

Sheffield J, Goteti G, Wood EF (2006) Development of a 50year high-resolution global dataset of meteorological forcings for land surface modeling. J Clim 19:3088-3111

Soil Landscapes of Canada Working Group (2010) Soil landscapes of Canada version 3.2. Agriculture and Agri-Food Canada (digital map and database at 1:1 million scale). http://sis.agr.gc.ca/cansis/nsdb/slc/v3.2/index.html

* Wang QJ, Nathan RJ (2007) A method for coupling daily and monthly time scales in stochastic generation of rainfall series. J Hydrol (Amst) 346:122-130

*Wang WG, Ding YM, Shao QX, Xu JZ, Jiao XY, Luo YF, Yu ZB (2017) Bayesian multi-model projection of irrigation requirement and water use efficiency in three typical rice plantation region of China based on CMIP5. Agric Meteorol 232:89-105

* Wang HM, Chen J, Cannon AJ, Xu CY, Chen H (2018) Transferability of climate simulation uncertainty to hydrological impacts. Hydrol Earth Syst Sci 22:3739-3759

*Webber H, Ewert F, Olesen JE, Müller C and others (2018) Diverging importance of drought stress for maize and winter wheat in Europe. Nat Commun 9:4249

Whitfield PH, Cannon AJ (2000) Recent variations in climate and hydrology in Canada. Can Water Resour J 25:19-65

Ye Z, Qiu X, Chen J, Cammarano D and others (2020) Impacts of $1.5^{\circ} \mathrm{C}$ and $2.0^{\circ} \mathrm{C}$ global warming above preindustrial on potential winter wheat production of China. Eur J Agron 120:126149

Submitted: August 31, 2020

Accepted: March 2, 2021

Proofs received from author(s): April 30, 2021 